\title{
Effect of vacuum sealing drainage on the expression of VEGF and miRNA-17-5p in seawater-immersed blast-injury wounds
}

\author{
FEN YANG ${ }^{1}$, BING SHI $^{2}$ and LING CAO ${ }^{2}$ \\ ${ }^{1}$ Department of Burns and Plastic Surgery, Bayannur City Hospital, Bayannur, Inner Mongolia 015000; \\ ${ }^{2}$ Department of Plastic and Reconstructive Surgery, The 309th Hospital of PLA, Beijing 100091, P.R. China
}

Received January 11, 2015; Accepted February 19, 2016

DOI: 10.3892/etm.2017.4057

\begin{abstract}
The aim of the present study was to compare and observe the expression levels of vascular endothelial growth factor (VEGF) and miRNA-17-5p during the treatment of seawater-immersed blast-injury wounds (SIBIW) under different conditions of vacuum sealing drainage (VSD), and to identify the optimized range of VSD treatment and partially explain its mechanisms. The bilateral hips and scapulae of experimental pigs (weight, $25-30 \mathrm{~kg}$ ) were subjected to blast-injury wounds, followed by the seawater immersion. The animals then underwent conventional dressing treatment under 120, 180 and $240 \mathrm{mmHg}$ VSD. Visual observation, in addition to histological, immunohistochemical and molecular biological techniques were applied to compare and observe the extent of wound healing and expression levels of VEGF and miRNA-17-5p. The wound healing of the VSD treatment group was improved compared with the control group, with $120 \mathrm{mmHg}$ negative pressure producing the most marked effect. miR-17-5p expression was detected in the SIBIW granulation tissues. There was significant difference between each VSD treatment group and control group at each time point $(\mathrm{P}<0.05)$. Thus, the present results show that miR-17-5p can be expressed in SIBIW granulation tissues, and this effect is most evident under $120 \mathrm{mmHg}$ negative pressure, which may inform the optimized negative range for the treatment of SIBIW.
\end{abstract}

\section{Introduction}

The development of modern marine industry and naval warfare has made human activities on the sea increasingly frequent. Thus, there has been an increase in the occurrence of various blast injuries being immersed by seawater, which may increase

Correspondence to: Professor Bing Shi, Department of Plastic and Reconstructive Surgery, The 309th Hospital of PLA, 17 Heishanhu Road, Beijing 100091, P.R. China

E-mail: bingshidoc@163.com

Key words: vacuum sealing drainage, seawater immersion, blast injury, miRNA, vascular endothelial growth factor tissue damage and thus affect wound healing. The prompt and effective treatment of seawater-immersed blast-injury wounds (SIBIW) has become a key topic in the field of trauma.

SIBIW is a class of damage caused under special circumstances, thus exhibiting various pathophysiological differences compared with ordinary trauma. Firstly, the explosion responsible for the wounding would rapidly generate a large quantity of high-pressure gas, heat and shock waves, resulting in lacerations, blast injuries and burns $(1,2)$. This trauma may result in skin and soft tissue loss, as well as causing damage to the surrounding tissues and body functions $(1,2)$. Secondly, the characteristics of seawater, including high salt, high alkali, easily permeating tissue and low temperature, may aggravate the infection of a wound, in addition to causing systemic microcirculation disorders, making the wounds difficult to heal or delay the healing, increasing the risk of mortality and morbidity (3). Vacuum sealing drainage (VSD) was first applied clinically by Dr Fleischmann (Ulm University, Ulm, Germany) in 1993 (4), and subsequent clinical practice has indicated that VSD may enhance the treatment of acute and chronic wounds and promote successful skin grafting (5-7). However, to date there are no reports investigating the application of VSD to SIBIWs.

The present study aimed to determine the effects of VSD treatments on SIBIWs under various negative pressure values by observing the general appearance, histology and vascular endothelial growth factor (VEGF)-immunohistochemistry of wounds, as well as the expression of angiogenesis-promoting regulation gene miRNA-17-5p and the wound microenvironment changes. In addition, the optimized pressure range of VSD in treating SIBIW was investigated, thus providing the basis for the clinical treatment of such trauma.

\section{Materials and methods}

Establishment of animal model and grouping. A total of eight No. I white Chinese miniature pigs were obtained (3 months of age; weight, 25-30 kg; male and female; provided by Liulihe Kexing Experimental Animal Breeding Center, Beijing, China) and received and intramuscular injection of sumianxin $0.2 \mathrm{ml} / \mathrm{kg}$ and $0.5 \mathrm{ml}$ midazolam (both Sigma-Aldrich; Merck Millipore, Darmstadt, Germany) as anesthesia. Then, the spine of each pig was set as the midline, and a blast-injury wound was formed on each limb and $10 \mathrm{~cm}$ from the midline, respectively, 
as previously described (8). After normal rapid debridement, the wounds were immersed into $10^{\circ} \mathrm{C}$ seawater for $1 \mathrm{~h}$, then rewarmed to body temperature. The animals were randomly divided into four groups: VSD treatment groups were administered 120, 180 and $240 \mathrm{mmHg}$ VSD, respectively; the control group wounds received conventional dressing and covered with saline gauze. VSD was performed for nine days, and the pigs were sacrificed after 58 days following anesthesia by intravenous 3\% sodium barbitone injection $(1 \mathrm{ml} / \mathrm{kg}$; Sigma-Aldrich; Merck Millipore). Samples with a diameter of 0.2-0.3 cm from the wound edge and central basal tissues were consecutively collected on days $1,3,5,7,9,16,23$ and 58 postoperation for the dynamic observation of wound healing situations. This study was conducted in strict accordance with the recommendations in the Guide for the Care and Use of Laboratory Animals of the National Institutes of Health. The animal use protocol has been reviewed and approved by the Institutional Animal Care and Use Committee of the 309th Hospital of PLA (Beijing, China).

General morphological observation. Wound size, swelling degree, wound edge, granulation tissue growth in the basilar wound part, epithelial coverage and wound healing degree were observed daily until day 58 following the operation.

Histological observation. The full-thickness skin tissues at the wound edge were sampled on days 1,3,5, 7 and 9 postoperation to assess wound formation using hematoxylin and eosin (HE) staining. The conditions of edema, inflammatory cell infiltration, angiogenesis, granulation tissue growth, epidermal proliferation and migration of the wound edge tissues were observed using light microscopy.

Immunohistochemical analysis. Paraffin sections $(2 \mu \mathrm{m})$ of samples were dewaxed and then washed with distilled water. After soaking in phosphate-buffered saline (PBS) for $5 \mathrm{~min}$, they were incubated with $3 \% \mathrm{H}_{2} \mathrm{O}_{2}$ at room temperature for $15 \mathrm{~min}$. After washing with PBS, the primary rabbit anti-VEGF polyclonal antibody (1:4,000; bs-1313R; Beijing Zhong Shan Jinqiao Biotechnology Development Co., Ltd., Beijing, China) was added and incubated at $37^{\circ} \mathrm{C}$ for $1-2 \mathrm{~h}$, followed by washing with PBS. Then, the biotinylated goat anti-rabbit IgG secondary antibody (1:200; bs-2331R; Beijing Zhong Shan Jinqiao Biotechnology Development Co., Ltd.) added and incubated at $37^{\circ} \mathrm{C}$ for $30 \mathrm{~min}$. After washing with PBS, 3,3'-diaminobenzidine staining was performed, followed by flushing with water, restaining, dehydration and mounting. The VEGF expression was observed using a fluorescence microscope.

Reverse transcription-quantitative polymerase chain reaction (RT-qPCR) for determination of miRNA-17-5p expression. Total RNA was extracted from the granulation tissues collected on days 1, 5, 9, 16 and 23 postoperation using TRIzol (Invitrogen; Thermo Fisher Scientific, Inc., Waltham, MA, USA) and digested with RNase-free DNase (Promega Corporation, Madison, WI, USA). The reverse transcription reaction with $300 \mathrm{ng}$ total RNA was performed using the PrimeScript First-strand cDNA Synthesis kit (Takara Biotechnology Co., Ltd., Dalian, China), according to the manufacturer's instructions. The primer sequences used in RT-qPCR were as following: miRNA-17-5p forward, 5'-GCTTCAACCCCTTCAAATGC-3' and reverse,
5'-GACGCAGAAGCGGTGTTATTG-3'; and $\beta$-actin forward 5'-GGAGATTACTGCCCTGGCTCCTA-3' and reverse, 5'-GACTCATCGTACTCCTGCTTGCTG-3'. The PCR system was as follows: SYBR Green 1 dye (Thermo Fisher Scientific Inc.), $5 \mu \mathrm{l}$; Premix Ex Taq (2X; Sangon Biological Engineering Co., Ltd., Shanghai, China), $7.5 \mu \mathrm{l}$; forward primer $(10 \mu \mathrm{mol} / \mathrm{l})$, $0.25 \mu \mathrm{l}$; reverse primer $(10 \mu \mathrm{mol} / \mathrm{l}), 0.25 \mu \mathrm{l}$; cDNA $(5 \mathrm{ng} / \mu \mathrm{l})$, $3 \mu \mathrm{l}$; and $\mathrm{dH}_{2} \mathrm{O}, 4 \mu \mathrm{l}$. The PCR thermal cycling conditions were as follows: $95^{\circ} \mathrm{C}$ for $20 \mathrm{sec} ; 40$ cycles at $95^{\circ} \mathrm{C}$ for $15 \mathrm{sec} ; 93^{\circ} \mathrm{C}$ for $30 \mathrm{sec} ; 55^{\circ} \mathrm{C}$ for $40 \mathrm{sec}$; and final extension at $72^{\circ} \mathrm{C}$ for $5 \mathrm{~min}$. The amplification and melting curve was recorded, and the expression of miRNA-17-5p was analyzed.

Statistical analysis. Data are expressed as the mean \pm standard deviation. The miRNA-17-5p detection data underwent statistical analysis using SPSS software, version 20.0 (IBM SPSS, Armonk, NY, USA). The comparison of miRNA-17-5p was performed using one-way analysis of variance. $\mathrm{P} \leq 0.05$ was considered to indicate a statistically significant difference.

\section{Results}

Visual general observation. The SIBIW surface was dirty with residual necrotic tissue in all groups, with a poorly-defined necrotic area, the substratum was pale, with less bleeding and a pale wound edge.

At day 1 after treatment, the effects of the 120,180 and $250 \mathrm{mmHg}$ VSD treatment groups were improved compared with the control group; with reduced swelling, dry wound surface and rosy basal tissues. By contrast, the wound edge of the control group had swelled, with increased necrotic tissues and pale substratum.

At day 3 after treatment, the wound surface of the $120 \mathrm{mmHg}$ treatment group was clean. By contrast, the other treatment groups exhibited secondary necrosis, with gray necrotic tissues in the wounds and evident exudate; the wound infection was severe, and the control group had increased necrotic tissue.

At day 5 after treatment, the wound substratum of the $120 \mathrm{mmHg}$ treatment group was rosy, the subcutaneous tissues under the scab were red. The wounds of the 180 and $240 \mathrm{mmHg}$ treatment groups were drier than previously, with reduced exudate and swelling, while the red swelling and exudation of the control group did not show any improvement.

At day 9 after treatment, all wound surfaces in the 120, 180 and $250 \mathrm{mmHg}$ VSD treatment groups were clean and dry, the substratum was pink, the granulation tissues were proliferated and the epidermal edge of wound began to migrate forward. Among which, the granulation tissues of the 120 and $180 \mathrm{mmHg}$ groups were plump and smooth, and the epidermis of these groups migrated the fastest.

Morphological observation. At day 1 after treatment the wound cells exhibited edema, partial cytoplasm transparency and mild staining. Focal inflammatory cell infiltration was visible, consisting predominantly of neutrophils and eosinophils. Compared with the control group, the VSD treatment group exhibited fewer inflammatory cells.

At day 3 after treatment the $120 \mathrm{mmHg}$ VSD treatment group exhibited no significant changes of inflammatory cells, while the edema of the other groups remained obvious, and 


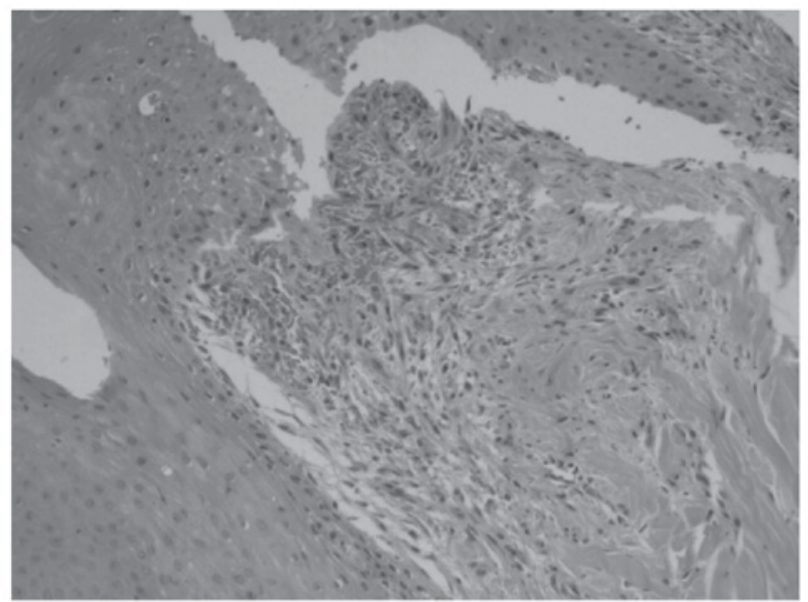

Figure 1. Obvious spindle fibroblasts at day 9 after treatment in the $120 \mathrm{mmHg}$ vacuum sealing drainage treatment group. Magnification, x10.
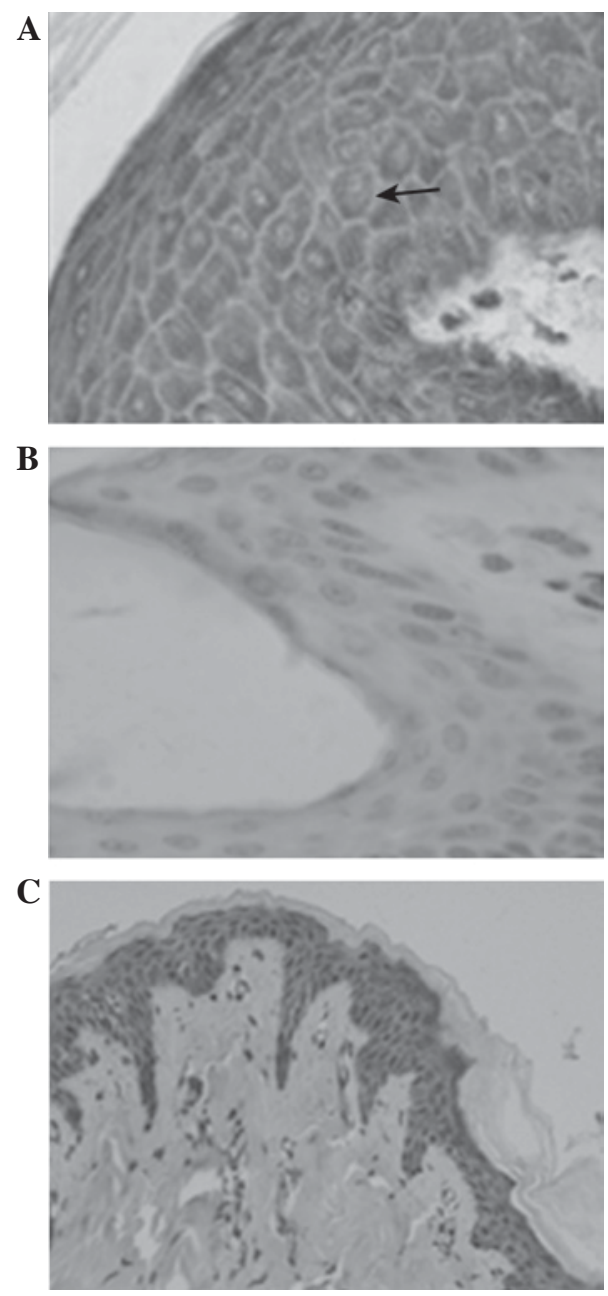

Figure 2. Vascular endothelial growth factor (VEGF) expression in cells. (A) Positive VEGF expression on day 9 at $2 \mathrm{~h}$ following traume in the $240 \mathrm{mmHg}$ vacuum sealing drainage group (arrow indicates VEGF expression). (B) Treatment group with $240 \mathrm{mmHg}$ on day 58. Trace positive VEGF expression in normal skin tissue. (C) Moderate positive VEGF expression in control group at day 58 after treatment. Magnification, x10.

the inflammatory cells were increased, exhibiting a diffused distribution.
At day 5 after treatment the VSD treatment group showed the growth of small quantity granulation tissue, among which the $120 \mathrm{mmHg}$ group was relatively obvious. The control group continued to exhibit a numerous inflammatory cells, with no significant granulation tissue growth.

At day 9 after treatment the cells had no significant swelling, with fewer inflammatory cells. All the treatment groups exhibited growth of granulation tissues, and the $120 \mathrm{mmHg}$ group exhibited the most growth (Fig. 1).

$V E G F$ expression. At $2 \mathrm{~h}$ following trauma, the positive VEGF expression increased in the epidermal cells, which was indicated by yellow/brown granules in the cytoplasm (Fig. 2A). There was only trace positive VEGF expression in normal skin tissue (Fig. 2B).

At day 1 after treatment, VEGF expression was detected in the treatment and control groups. Numerous yellow granules were visible within the epidermal cellular cytoplasm of wound peripheral tissues. The expression of VEGF in the $120 \mathrm{mmHg}$ group was higher in comparison with the other treatment groups and the control group.

Between days 5 and 9 after treatment, the VEGF expression in the cytoplasm continued to increase, peaking on day 9. The $120 \mathrm{mmHg}$ group continued to exhibit the most significant expression, with brown granules uniformly distributed within the cytoplasm. At day 58 following treatment, the wound healed and the expression of VEGF in the cytoplasm was significantly decreased, less expressed in the VSD group, and that in the $20 \mathrm{mmHg}$ group was close to the normal skin tissues; while there still was moderate expression in the control group (Fig. 2C).

miRNA-17-5p detection. The quality detection of RNA showed that the RNA expression was stable and within the normal limits, and the gel electrophoresis indicated that the RNA was integral (Fig. 3). RT-qPCR identification revealed that the amplification of ssc-17-5p primer was good, and the qPCR primers could effectively and specifically amplify the corresponding RNA fragments (Fig. 4).

miRNA-17-5p expression was detected in the SIBIW granulation tissues, and the expression in the VSD treatment group was higher compared with the control group. The expression in the VSD treatment group peaked at day 1 after treatment, and the expression detected in the $180 \mathrm{mmHg}$ group was higher compared with the other treatment groups, Over time, the miRNA-17-5p expression gradually decreased, while the expression levels in the $120 \mathrm{mmHg}$ group remained continuously higher than the other treatment groups, and the expression of the control group exhibited the dynamic trend. There was significant difference at each time point between the 120, 180 and $250 \mathrm{mmHg}$ VSD treatment groups and the control group $(\mathrm{P}<0.05)$ (Fig. 5).

\section{Discussion}

Wound healing involves a series of complex pathophysiological processes, which includes the inflammation, proliferation and migration of repaired cells, in addition to the formation and tissue remodeling of granulation tissues (9). Factors that are able to disrupt these processes may impact wound 

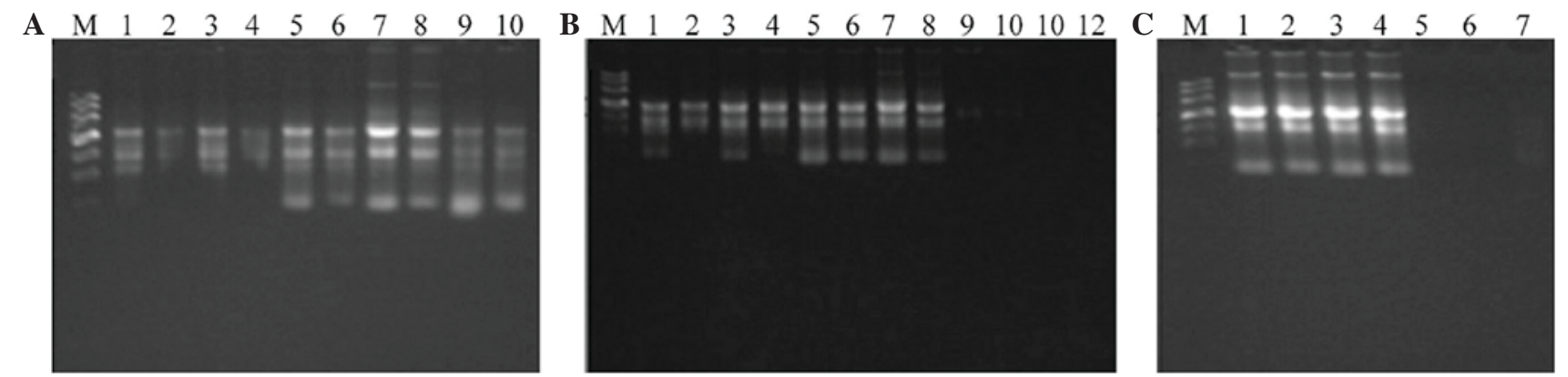

Figure 3. Electrophoresis of RNA. The numbers represent the different samples. (A) 1, A5d-2-1, 2, A5d-2-2; 3, A5d-3-1; 4, A5d-3-2; 5, A5d-4-1; 6, A5d-4-2; 7, A9d-2-1; 8, A9d-2-2; 9, A9d-3-1; and 10, A9d-3-2. (B) 1, A5d-1-1, 2, A5d-1-2; 3, A9d-1-1; 4, A9d-1-2; 5, A16d-1-1; 6, A16d-1-2; 7, A23d-1-1; 8, A23d-1-2; 9, A0d-0-1; 10, A0d-0-2; 11, A1d-1-1; and 12, A1d-1-2. (C) 1, A23d-3-1, 2, A23d-3-2; 3, A23d-4-1; 4, A23d-4-2; 5, A1d-2-2; 6, A1d-3-1; and 7, A1d-4-1.
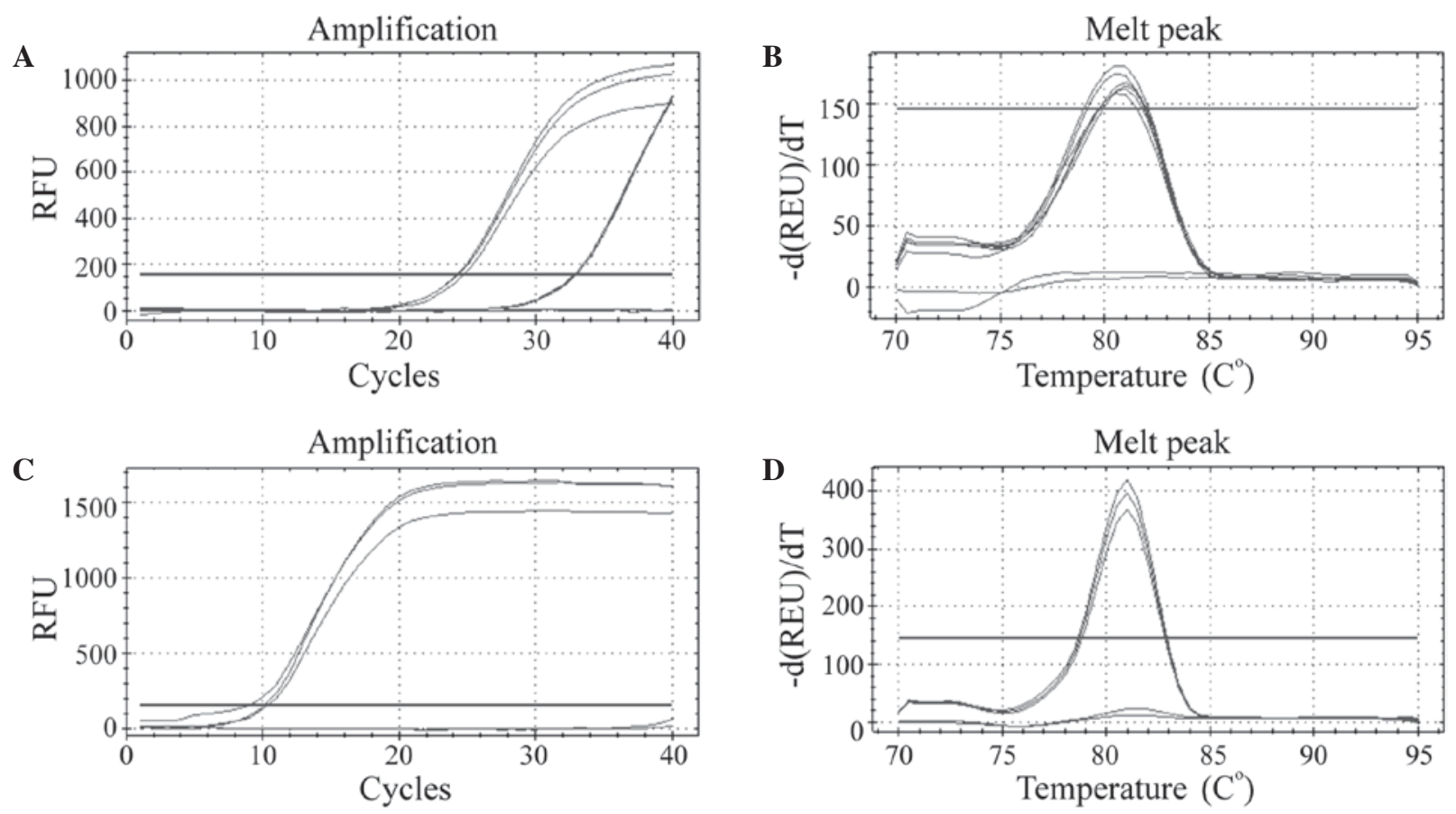

Figure 4. Amplification and melting curves of ssc-miRNA-17-5p and $\beta$-actin. (A) Amplification curve of ssc-miRNA-17-5p; (B) Melting curve of ssc-miRNA-17-5p; (C) Amplification curve of $\beta$-actin; (D) Melting curve of $\beta$-actin.

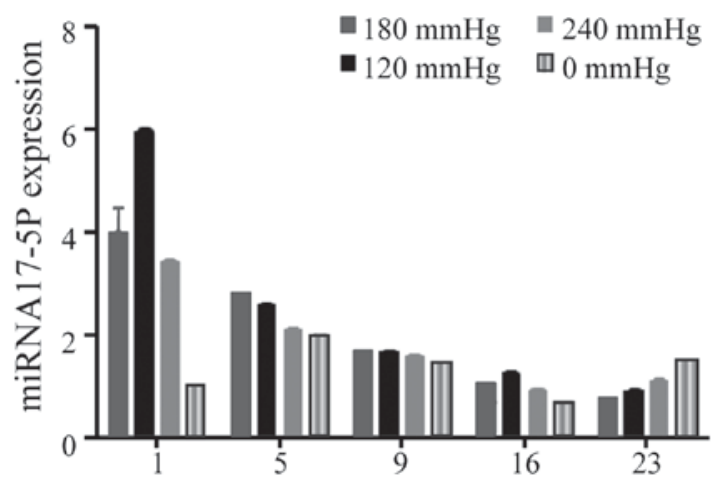

Figure 5. miRNA-17-5p expression levels in the vacuum sealing drainage and control groups on days $1,5,9,16$ and 23 following surgery. There was a significant difference at each time point between each vacuum sealing drainage treatment group and the control group $(\mathrm{P}<0.05)$.

healing. SIBIWs are obviously different to general injuries due to their particular characteristics (10).
Seawater immersion may increase tissue damage; SIBIW is a type of complex and comprehensive damage (11). The tissues at the wounds have various injury factors, and are typically accompanied by extensive damage ranges, ill-defined necrotic tissues, heavily contaminated wounds, as well as different ranges of skin and soft tissue defects (12). Seawater has a complex composition, and may contain a variety of bacteria, and $\mathrm{pH}$ and osmolality are higher than the normal value in humans. Furthermore, in the majority of regions, seawater temperature is $<20^{\circ} \mathrm{C}$, which is lower than the human body temperature (13). These factors result in seawater exhibiting high permeability, high alkalinity, diverse flora and low temperature. The environment of high permeability and alkalinity could aggravate the damage in wounded tissues and cells, and enhance edema; various bacteria could induce complex and diverse infections. Inflammation would be difficult to control and long-term low temperature could potentially result in severe cardiovascular disorders, metabolic acidosis and blood circulation disorders, 
thus accelerating the wound tissue necrosis and increasing local wound damage (14).

Since the introduction of VSD into clinics, and its application to various types of wound treatment, it has achieved potentially promising results (15-17). A previous study showed that VSD could perform the adequate drainage, so that wounds are thoroughly cleaned and fully prevented the formation of subcutaneous space (18). Thus, the removal of necrotic tissue is promoted and the growth of bacterial cultures is reduced; reduce the secretion of inflammatory mediators and toxic substances and reduce the wound edema and swelling (19). In addition, VSD has been suggested to increase wound blood flow and expand blood vessel diameter, thus improving blood circulation and nutrient supply to wounded tissue $(20,21)$. VSD may also reduce the quantity of acidic substances in a wound, promote nutrient absorption and oxygen usage, the growth of granulation tissues, wound fibroblasts and capillary endothelial cells, thus conducive to regeneration of dermis (22-24). Huljev (20) and Atay et al (25) found that VSD could also effectively reduce the production of wound matrix metalloproteinase, and inhibit its activity, thereby promoting collagen synthesis, which would be favor for wound healing.

During the wound healing process, the degree of inflammation and vascular proliferation substantially impact wound healing. Inflammation is the body's own defensive process; however, excessive inflammation could exacerbate tissue damages, leading to mitigated wound healing (26). Furthermore, angiogenesis may provide more nutrients to the wound, thus accelerating wound healing.

Through the naked-eye general sample observation, the present study found that on day 1 following treatment, the wound swelling of the VSD treatment group was mild, with limited oozing and no significant necrotic tissues, while the wound swelling of the control group was significant, with gray necrotic tissues. On day 3 after treatment, the 180 and $240 \mathrm{mmHg}$ VSD treatment groups and the control group exhibited secondary necrosis, with increased wound swelling and significant infection. On day 5 after treatment, the VSD treatment group exhibited reduced wound exudate and necrotic tissue, while the control group had increased necrotic tissue and exudate. On day 9, all wound swelling regressed, the infections disappeared and the granulation tissues grew. The wound of the $120 \mathrm{mmHg}$ group remained clean and dry, with no obvious discharge or secondary necrosis. The granulation tissues grew well, and epidermal forward-migration was faster.

Histological analysis of tissues collected on day 1 revealed edema and focal inflammatory cells, which were predominantly neutrophils and eosinophils. On day 3, with the exception of the $120 \mathrm{mmHg}$ group, there was extensive inflammatory cell infiltration in the other groups. On day 5, only the $120 \mathrm{mmHg}$ group exhibited the growth of granulation tissue, the number of inflammatory cells in the 180 and $240 \mathrm{mmHg}$ groups were decreased, while the control group continued to exhibit a large number of inflammatory cells. On day 9, all wounds exhibited the growth of granulation tissue. These results indicate that VSD may be able to effectively reduce inflammation and secondary necrosis in SIBIWs, promote the growth of granulation tissue, and accelerate the wound healing, among which the $120 \mathrm{mmHg}$ group exhibited the most marked therapeutic effects.
Good blood circulation is key to the wound healing, and the formation of granulation tissues may aid in providing sufficient blood towards the wound. Granulation tissues could provide the regenerated tissues with oxygen and nutrients, while repairing tissue defects, promoting the absorption of necrotic tissues and helping to control inflammation (24). Granulation tissues are composed of nascent thin-walled capillaries and proliferated fibroblasts, in which the regeneration of capillaries and the formation of a vascular network are crucial. VEGF has been shown to be a unique growth factor, specific to the process of angiopoiesis.

The present results showed that VEGF was positive expressed in the cytoplasm of VSD-treated tissues, while normal skin tissues showed a relatively moderate amount of expression. Comparisons among the various VSD treatment groups and the control group revealed that the expression of VEGF in the VSD treatment group at day 1 was higher than the control group, particularly in the $120 \mathrm{mmHg}$ group, which reached the highest level on day 9 after treatment. Subsequent to day 9 , the wound healing was decreased. Histological observation revealed that on day 5 , the $120 \mathrm{mmHg}$ group began to exhibit the growth of granulation tissues, while on the day 9 , all the wounds exhibited the growth of granulation tissues. Therefore, it was hypothesized that VSD could increase the expression of VEGF, promote the growth of granulation tissues and accelerate wound healing; particularly at a negative pressure of $120 \mathrm{mmHg}$.

In previous years, molecular biology studies have discovered that miRNAs may regulate the expression of multiple genes inside the organism, thus affecting such physiological activities as growth and development of the body $(27,28)$. With regard to wound healing, miRNAs may be able to regulate the angiogenesis, migration and regeneration functions of epithelial cells, thus affecting the wound healing process (29). Suárez et al (30) found in a study of ischemia and reperfusion that miR-17-5p could regulate the functions of endothelial cells, thus promoting the angiogenesis. Otsuka et al (31) studied the luteal functions of infertile mice, and further demonstrated that miR-17-5p could affect the endothelial cell functions via the inhibition of metalloproteinase 1 (TIMP-1), thus promoting angiogenesis. Furthermore, previous studies have indicated that miR-17-5p plays a role in the promotion of angiogenesis $(32,33)$. However, previous studies regarding the angiogenic promotion effects of miR-17-5p have not investigated its expression in wounds.

The present result showed increased miR-17-5p expression in the granulation tissues of SIBIWs; with the expression in the $120 \mathrm{mmHg}$ VSD group significantly higher compared with the control group. In the $180 \mathrm{mmHg}$ VSD treatment group, the expression on day 1 was the highest, and decreased gradually over time. By contrast, the expression in the control group appeared as a change in the lower level. The naked-eye general and histological observations suggest that the granulation tissues of the $240 \mathrm{mmHg}$ VSD treatment group grew significantly, and that wound healing was more rapid. Therefore, it was hypothesized that miR-17-5p could regulate endothelial cell functions in the early stage of wound healing, thus promoting angiogenesis, increasing the growth of granulation tissues and accelerating wound healing. In addition, at day 1 after treatment, the miR-17-5p expression in the $180 \mathrm{mmHg}$ 
group was significantly increased, while in the subsequent treatments, the expression in the $120 \mathrm{mmHg}$ group was continuously higher compared with the other groups. These results indicated that the expression of miR-17-5p under $120 \mathrm{mmHg}$ treatment produced the most marked therapeutic effects.

In conclusion, we speculated that VSD could effectively reduce the inflammation, infection and secondary necrosis of SIBIWs, in addition to promoting the growth of granulation tissues, accelerating epithelial migration and increasing miR-17-5p expression. The therapeutic effects of $120 \mathrm{mmHg}$ were more marked compared with 180 and $240 \mathrm{mmHg}$; however, it remains unclear whether this represents the optimal negative pressure for SIBIW treatment, and further studies are required.

\section{References}

1. Kirkman E and Watts S: Haemodynamic changes in trauma. $\mathrm{Br}$ J Anaesth 113: 266-275, 2014.

2. Ning J, Mo L, Zhao H, Lu K, Wang L, Lai X, Yang B, Zhao H, Sanders RD and Ma D: Transient regional hypothermia applied to a traumatic limb attenuates distant lung injury following biast limb trauma. Crit Care Med 42: e68-e78, 2014.

3. Liu P, Liu JC, Lai XN, Peng XL, Wu GP, Zhang LC and Wang LL: Pathological study of rabbits' femoral arteries subjected to gunshot wounds combining with seawater immersion. Chin J Traumatol 8: 186-190, 2005.

4. Fleischmann W, Strecker W, Bombelli M and Kinzl L: Vacuum sealing as treatment of soft tissue damage in open fractures. Unfallchirurg 96: 488-492, 1993.

5. Witkowski W, Jawien A, Witkiewicz W and Zon B: Initial multi-centre observations upon the effect of a new topical negative pressure device upon patient and clinician experience and the treatment of wounds. Int Wound J 6: 167-174, 2009.

6. Scherer LA, Shiver S, Chang M, Meredith JW and Owings JT: The vacuum assisted closure device: A method of securing skin grafts and improving graft survival. Arch surg 137: 930-934; discussion 933-934, 2002.

7. Zhang C, Liu DR, Liang Z, Liu F, Lin H and Guo Z: Reapair of refractory wounds through grafting of artificial dermis and autologous epidermis aided by vacuum-assistde closure. Aesthetic Plast Surg 38: 727-732, 2014.

8. Li XY, Li JQ, Chen SZ, Li WZ and Li YJ: Establishment of animal model of blast injury in pig skin and soft tissue. Zhong Hua Shi Yan Wai Ke Za Zhi 12: 1551-1553, 2006 (in Chinese).

9. Pazyar N, Yaghoobi R, Rafiee E, Mehrabian A and Feily A: Skin wound healing and phytomedicine: A review. Skin Pharmacol Physio 2: 303-310, 2014.

10. Cao L, Peng MM, Sun JJ, Yu XC and Shi B: Application of vacuum-assisted closure in seawater-immersed wound treatment under different negative pressures. Genet Mol Res 14: 6146-6155, 2015.

11. Shi B, Sun J, Cao Y, Yang F, Wu Y, Liang X and Li L: Application of vacuum sealing drainage to the treatment of seawater-immersed blast-injury wounds. Int Wound J: May 8, 2015 (Epub ahead of print).

12. Popov VL, Kadochnikov DS and Minaeva PV: The role of the biological damaging factor in the explosive injury. Sud Med Ekspert 58: 20-23, 2015.

13. Diaz JH: Skin and soft tissue infections following marine injuries and exposures in travelers. J Travel Med 21: 207-213, 2014.

14. Diaz JH and Lopez FA: Skin, soft tissue and systemic bacterial infections following aquatic injuries and exposures. Am J Med Sci 349: 269-275, 2015 .
15. Wolvos TA: Negative pressure wound therapy with instillation: The current state of the art. Surg Technol Int 24: 53-62, 2013.

16. Frick A, Wallmichrath J, Frick G, Giunta RE and Engelhardt TO: Difficult wounds \& vacuum assisted closure (VAC). MMW Fortschr Med 155: 63-64, 2013 (In German).

17. Altintas B, Biber R and Brem MH: The accelerating effect of negative pressure wound therapy with Preven $\mathrm{a}^{\mathrm{TM}}$ on the healing of a closed wound with persistent serous secretion. Int Wound J 2014 (Epub ahead of print).

18. Zhang WH, Wu Q, Ma J and Wang JH: Effects of vacuum drainage combined with heparin irrigation for treatment of scald burns with seawaterimmersion in rabbits. Nan Fang Yi Ke Da Xue Xue Bao 35: 1481-1486, 2015 (in Chinese).

19. Ingber DE: Tensegrity I. Cell structure and hierarchical systems biology. J Cell Sci 116: 1157-1173, 2003.

20. Huljev D: Negative pressure therapy-supportive method in chronic wound treatment. Acta Med Croatica 67 (Suppl 1): S89-S94, 2013 (In Croatian).

21. Borrero Esteban MP, Begines Begines R, Rodríguez Llamas S and Díaz Campos T: Managing complications in severe traumatic injury with VAC therapy with instillation. Rev Enferm 36: 42-47, 2013 (In Spanish).

22. Malmsjö M, Lindstedt S, Ingemansson R and Gustafsson L: Use of bacteria- and fungus-binding mesh in negative pressure wound therapy provides significant granulation tissue without tissue ingrowth. Eplasty 14: e3, 2014.

23. Harish V and Maitz PK: Uninterrupted continuous negative pressure wound therapy is safe and can facilitate engraftment of dermal regeneration templates. J Plast Reconstr Aesthet Surg 67: 1011-1013, 2014.

24. Pitt KA and Stanley BJ: Negative pressure wound therapy: Experience in 45 dogs. Vet Surg 43: 380-387, 2014.

25. Atay T, Burc H, Baykal YB and Kirdemir V: Results of vacuum assisted wound closure application. Indian J Surg 75: 302-305, 2013

26. Roy $\mathrm{S}$ and Sen CK: miRNA in wound inflammation and angiogenesis. Microcirculation 19: 224-232, 2012.

27. Hildebrand J, Rütze M, Walz N, Gallinat S, Wenck H, Deppert W, Grundhoff A and Knott A: A comprehensive analysis of microRNA expression during human keratinocyte differentiation in vitro and in vivo. Invest Dermatol 131: 20-29, 2011.

28. Zhang L, Stokes N, Polak L and Fuchs E: Specific microRNAs are preferentially expressed by skin stem cells to balance self-renewal and early lineage commitment. Cell Stem Cell 8: 294-308, 2011

29. Chen Y and Gorski DH: Regulation of angiogenesis through a microRNA (miR-130a) that down-regulates antiangiogenic homeobox genes GAX and HOXA5. Blood 111: 1217-1226, 2008.

30. Suárez Y, Fernández-Hernando C, Yu J, Gerber SA, Harrison KD, Pober JS, Iruela-Arispe ML, Merkenschlager M and Sessa WC: Dicer-dependent endothelial microRNAs are necessary for postnatal angiogenesis. Proc Natl Acad Sci USA 105: 14082-14087, 2008.

31. Otsuka M, Zheng M, Hayashi M, Lee JD, Yoshino O, Lin S and Han J: Impaired microRNA processing causes corpus lustrum insufficiency and infertility in mice. J Clin Invest 118: 1944-1954, 2008.

32. Ramón LA, Braza-Boïls A, Gilabert J, Chirivella M, España F Estellés A and Gilabert-Estellés J: microRNAs related to angiogenesis is deregulated in endometriosis endometrial cancer. Hum Reprod 27: 3036-3045, 2012.

33. Bonauer A, Carmona G, Iwasaki M, Mione M, Koyanagi M, Fischer A, Burchfield J, Fox H, Doebele C, Ohtani K, et al: MicroRNA-92 a controls angiogenesis and functional recovery of ischemic tissues in mice. Science 324: 1710-1713, 2009. 